\title{
Improved Performance of Carbamazepine and Benzodiazepine by Oxygen Enrichment through Perfluorodecalin for Lennox-Gastaut Type of Seizures
}

\author{
V. NATCHIMUTHU*, S. RAVI ${ }^{1}$ AND J. AMOROS ${ }^{2}$
}

Department of Physics, M.Kumarasamy College of Engineering, Karur, Tamil Nadu 639113, ${ }^{1}$ Department of Physics, National College (Affiliated to Bharathidasan University), Karumandapam, Tiruchirapalli, Tamil Nadu 620001, India, ${ }^{2}$ Department of Applied Physics, University of Cantabria, Avda, Los Castros, Santander 39005, Spain

Natchimuthu et al.: Oxygen Enrichment through Perfluorodecalin

\begin{abstract}
Lennox-Gastaut syndrome is commonly characterized by a triad of features including multiple seizure types, intellectual disability or regression. The long-term prognosis for Lennox-Gastaut syndrome is generally poor due to uncontrolled seizures. Lennox-Gastaut syndrome type of seizures is epilepsy which is due to abnormal vibrations occurring in seizures. During the time of such abnormal vibrations, both the seizures and the lungs suffer a lack in oxygen content to a considerable extent. This results in prolonged vibrations and loses of nervous control. As a neuro-lung protective strategy, a novel attempt has been made to enrich both seizures and lungs with oxygen content through the support of perfluorodecalin (an excellent oxygen carrier) $C_{10} F_{18}$ along with an enhancement in the antiepileptic activity by the two chosen antiepileptic drugs carbamazepine and benzodiazepine. The ultraviolet-visible spectrophotometer, fluorescence spectrograph, ultrasonic laser diffraction and scanning electron microscope studies reveals the co-existence of fluorine and drug in the emulsion produced by the sonication of both perfluorodecalin and the drug together. The presence of adequate fluorine and carbon play a catalytic role in ensuring the oxygen content and the antiepileptic activity of drug components.
\end{abstract}

Key words: Antiepileptic drugs, seizures, fluorescence spectrograph, ultrasonic laser diffraction, perfluorodecalin, oxygen enrichment

Lennox-Gastaut type of syndrome is complex epilepsy occurring due to abnormality in seizures. Control of seizures is difficult. An unexpected disharmony in seizures results in epilepsy. Drugs that are most preferred and prescribed for such kind of disease causes adverse side effects. Further any new drug for that matter faces such problems and their effectiveness on the affected seizures is still an unsolved problem ${ }^{[1-10]}$.

Though the valid reasons for the abnormal behavior of seizures, at any particular time, are still a mystery, there seems to be an in adequacy in the supply of oxygen content to both the seizures and lungs. Patients affected by such problems, happens to find it difficult to breath freely, tends to lose the nervous balance. Seizures, at the time of abnormal vibrations, lack in oxygen content and hence the abnormal vibrations prolongs for a longer period of time ${ }^{[11-16]}$.

As a neuro-lung protective strategy, a novel attempt has been made through this paper to apply the

*Address for correspondence

E-mail: natchimuthu88@gmail.com

July-August 2021 phenomenon of oxygen enrichment to both seizures (brain) and lungs simultaneously with the support of perfluorodecalin $\mathrm{C}_{10} \mathrm{~F}_{18}$ (PFD). At the same time the antiepileptic activity is expected to enhance through the chosen antiepileptic drugs (AEDs) like carbamazepine (CBZ) and benzodiazepine (BDZ). Though valproate, topiramate and lamotrigine are deemed to be first line drugs, CBZ and BDZ are chosen for this study because of their simple structures and could be more adaptive to accommodate such fluorinated compounds.

The incorporation of one or more fluorine atoms into a compound can have a dramatic effect on its chemical and physical properties and fluorinated molecules

This is an open access article distributed under the terms of the Creative Commons Attribution-NonCommercial-ShareAlike 3.0 License, which allows others to remix, tweak, and build upon the work non-commercially, as long as the author is credited and the new creations are licensed under the identical terms

Accepted 20 August 2021

Revised 07 April 2021

Received 17 November 2020 Indian J Pharm Sci 2021;83(4):848-855 
are of considerable importance in a wide range of industries including pharmaceuticals, agrichemicals, medical imaging, plastics, polymers and electronics. However the synthesis of these important molecules is fundamentally difficult due to the high reactivity of fluorinating agents.

To achieve, either one has to come out with a novel drug containing fluorine compounds and the suitable AEDs, both as single organized structure (in the form of a single crystal) or try to convert both the drug and the PFD into an emulsified mixture and study their predominant contents and assess the particle diameter.

The above said first notion is purely optional and PFD is absolutely neutral by structure. It is quite difficult to break any of its bonds and to make it reactive with either $\mathrm{CBZ}$ or BDZ. Though the neutral structure of PFD is not so conducive for a perfect chemical reaction, the basic reason for choosing $\mathrm{C}_{10} \mathrm{~F}_{18}$ is due to the fact that it is an excellent oxygen carrier ${ }^{[17,18]}$. Chemically it is highly electronegative. The role of PFD in cardiopulmonary by-pass, lung ventilation, ventilation fluids, cellculture supplement, diagnostic imaging agents, drug formulation and delivery were extensively proved ${ }^{[19-23]}$.

In spite of all these applications their perfect neutral chemical structure is not supportive for any chemical reaction with any compounds. The only effective way to use them is to convert them into an emulsion. There are decent numbers of studies substantiating the excellent oxygen carrying capacity of PFD in emulsified form ${ }^{[24-}$ ${ }^{31}$. Based on the above said facts the second idea is more viable. To achieve these following steps were adopted.

\section{MATERIALS AND METHODS}

CBZ, BDZ and PFD used as $99 \%$ pure acquired from Sigma-Aldrich. They are used without any further purification. Dimethylformamide (DMF) is used as an effective solvent.

In the first step, $100 \mathrm{mg}$ of $\mathrm{CBZ}$ and BDZ each are dissolved in $30 \mathrm{ml}$ of DMF to prepare high concentrated solutions. Ultrasonic laser diffraction (ULD) has been performed to determine the sound velocity through the solution and the compressibility is estimated. The results are tabulated in Table 1. Both the high concentrated solutions were subjected to ultravioletvisible (UV-VIS) spectrographic and fluorescence spectrophotograph studies to analyze the intensity and position of the peaks of the pure $\mathrm{CBZ}$ and $\mathrm{BDZ}$ drugs exclusively. The study is repeated for very low concentrated solutions too. The reports are presented in fig. 1-fig. 6.

In second step, it involves a continuous process of mixing $10 \mathrm{ml}$ of PFD to the high concentration solution

TABLE 1: ULD DATA

\begin{tabular}{|c|c|c|c|c|}
\hline S. No & Sample & $\begin{array}{l}\text { Ultrasonic velocity }(\mathrm{U}) \\
{[\mathrm{m} / \mathrm{s}]}\end{array}$ & Density $(\rho)\left[\mathrm{Kg} / \mathrm{m}^{3}\right]$ & $\begin{array}{c}\text { Adiabatic } \\
\text { compressibility }(\mathrm{K}) \\
\times 10^{-10}\left[\mathrm{~Pa}^{-1}\right]\end{array}$ \\
\hline 1. & $\operatorname{PFD}\left(\mathrm{C}_{10} \mathrm{~F}_{18}\right)$ & 636.2455 & 1930.00 & 12.7995070 \\
\hline 2. & $\mathrm{DMF}+\mathrm{CBZ}(100 \mathrm{mg})$ & 1345.8536 & 956.8404 & 5.76985441 \\
\hline 3. & $D M F+C B Z(100 \mathrm{mg})+10 \mathrm{ml} \mathrm{C}_{10} \mathrm{~F}_{18}$ & 1409.8712 & 1123.7762 & 4.47673402 \\
\hline 4. & $\mathrm{DMF}+\mathrm{BDZ}(100 \mathrm{mg})$ & 1227.6678 & 966.3566 & 6.86595342 \\
\hline 5. & $D M F+B D Z(100 \mathrm{mg})+10 \mathrm{ml} \mathrm{C}_{10} \mathrm{~F}_{18}$ & 1296.9243 & 1093.2526 & 5.43813802 \\
\hline
\end{tabular}

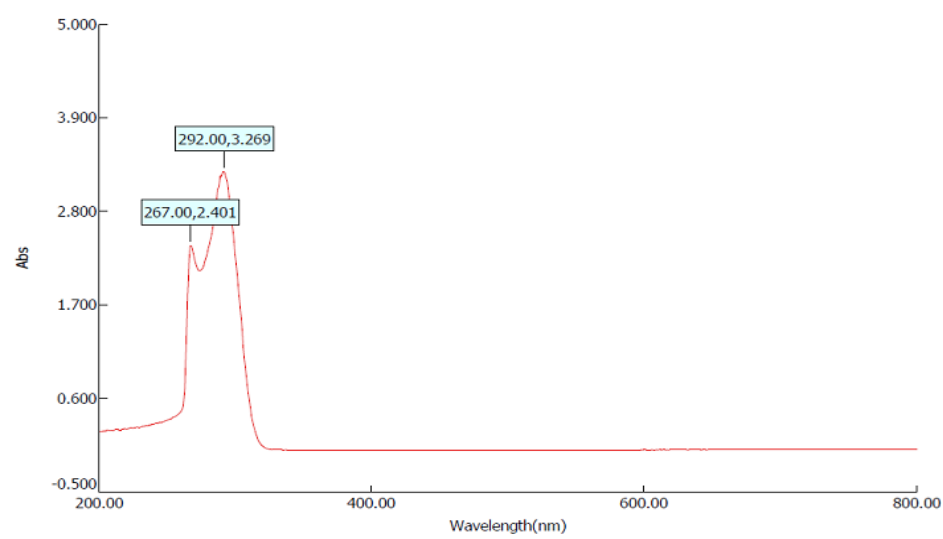

Fig. 1: UV spectrum of BDZ in DMF at high concentration (1 mmol) 
www.ijpsonline.com

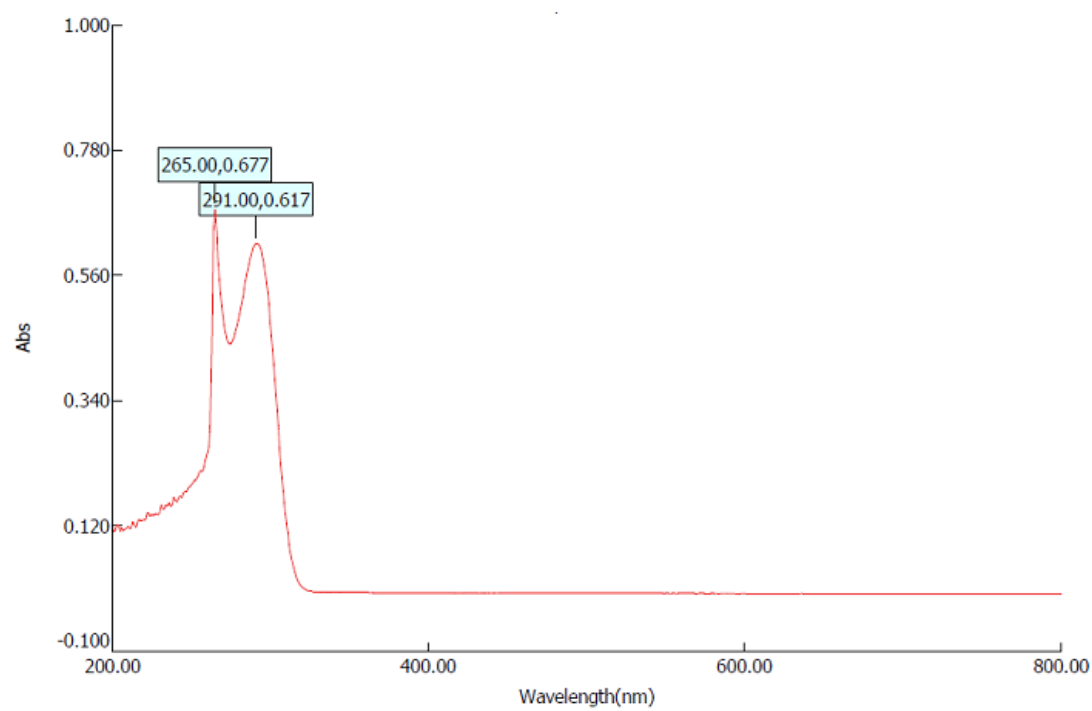

Fig. 2: UV spectrum of BDZ in DMF at low concentration (0.1 mmol)

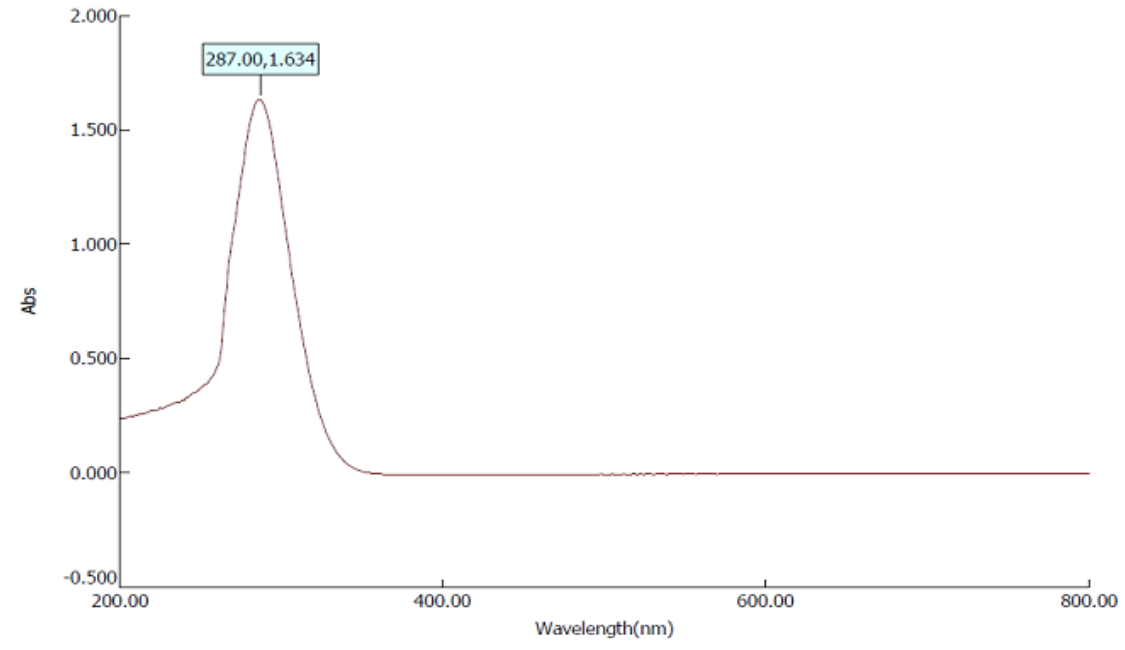

Fig. 3: UV spectrum of CBZ in DMF at high concentration (2 mmol)

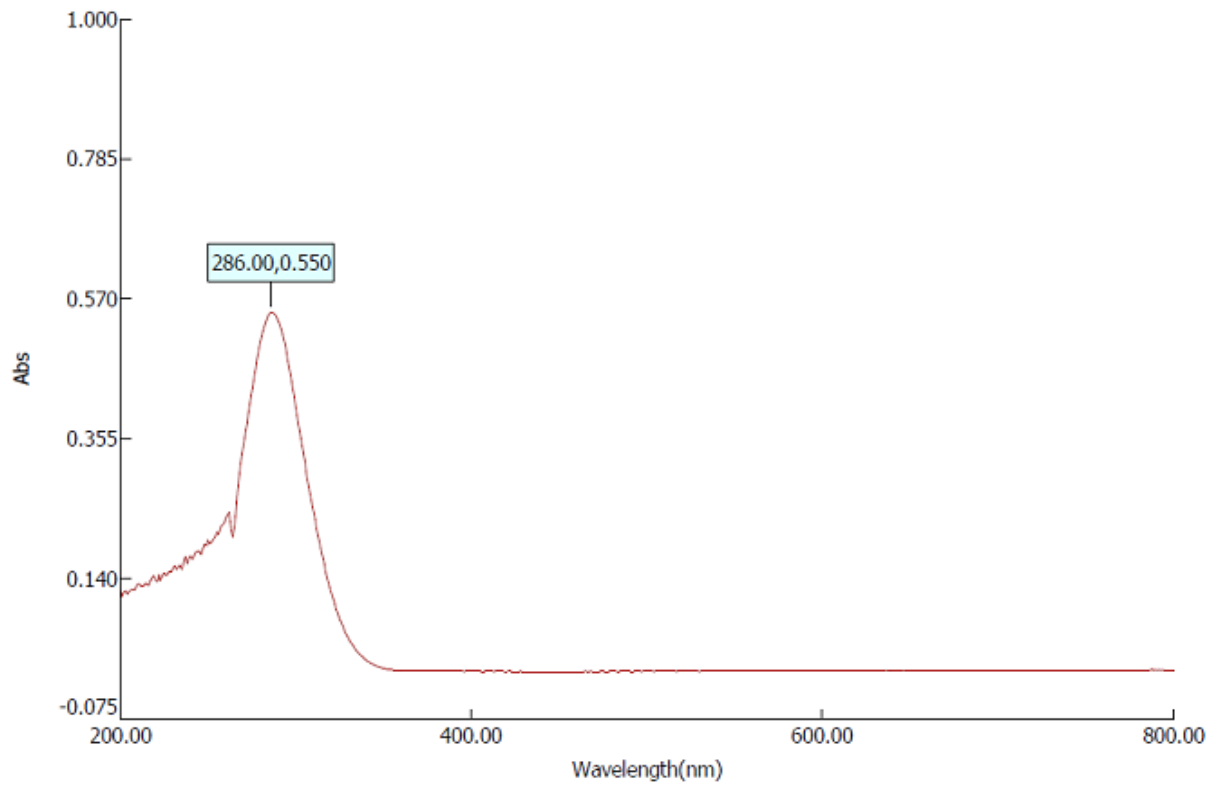

Fig. 4: UV spectrum of CBZ in DMF at low concentration (0.2 mmol) 
of both $\mathrm{CBZ}$ and BDZ each. This mixture has been sonicated at $40 \%$ amplitude and $5 \mathrm{KHz}$ frequency for $5 \mathrm{~min}$ at a time interval of $1 \mathrm{~min}$. At most care has been taken to reduce the heat by using dry ice cage. The emulsion formed is preserved at $-10^{\circ}$ in a cryostat for $5 \mathrm{~d}$. On the $6^{\text {th }} \mathrm{d}$ a part of the emulsion is diluted to low concentration. Again UV-VIS, fluorescence and ULD studies are performed. The images are presented in fig. 7- fig. 10 and in Table 1. In third step, the emulsion is placed for slow evaporation process at $313 \mathrm{~K}$. The obtained powder is subjected for scanning electron microscope (SEM) analysis. The results are reported in fig. 11 and fig. 12.

\section{Apparatus:}

The UV-VIS spectrophotometer is a 20-1950-910029 made with a spectral bandwidth of $2.00 \mathrm{~nm}$ is used. The fluorescence spectrophotometer is high sensitive RF-5301-EM made with a scan range of $300.00 \mathrm{~nm}-500.00 \mathrm{~nm}$. The ULD diffractometer used is of Holmarc-international made. The frequency ranges from $3-10 \mathrm{MHz}$ and the laser wavelength is $6000 \mathrm{~nm}$. The ultrasonic-homogenizer is of PCI international made with a sweep frequency of $1-10 \mathrm{KHz}$ containing a platinum probe. The scanning electron microscopyenergy dispersive $\mathrm{x}$-ray spectroscopy (SEM-EDS) analysis was performed in TESCAN microscope at the operating voltage of $10-20 \mathrm{kV}$. The images were processed with Vega 3 software system and then probed $^{[32]}$.

\section{RESULTS AND DISCUSSION}

The UV-VIS and fluorescence images presented in fig. 1-fig. 6 are highly encouraging. The wavelength of pure CBZ and BDZ correlates nicely with standard results though the solvent chosen is DMF. There is a

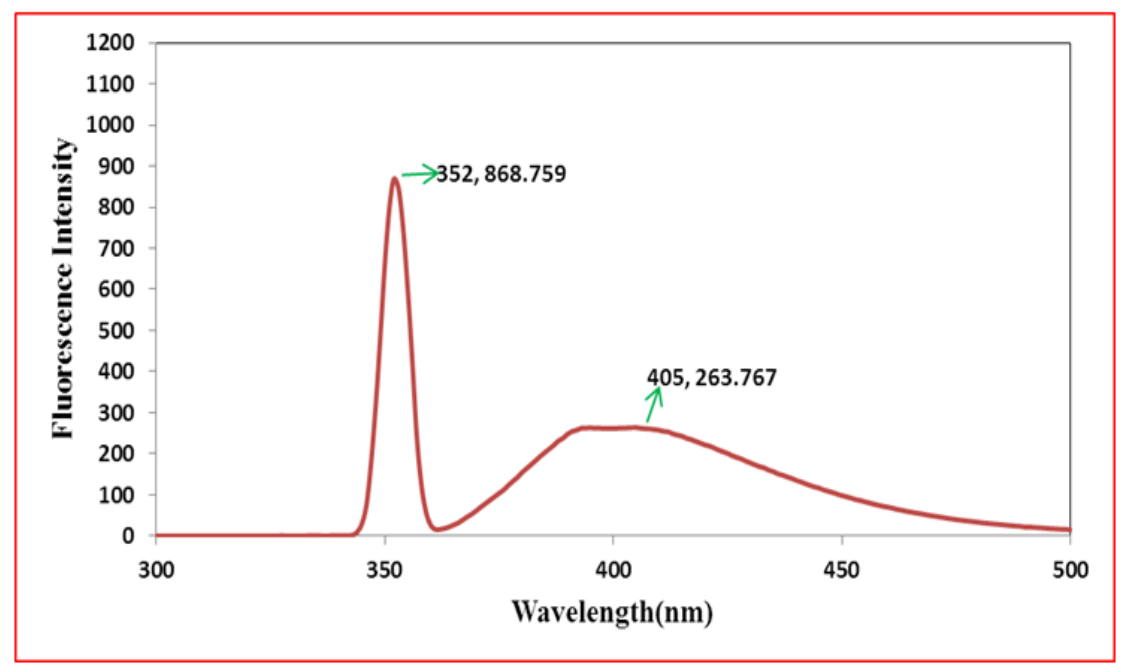

Fig. 5: Fluorescence spectrum of BDZ in DMF

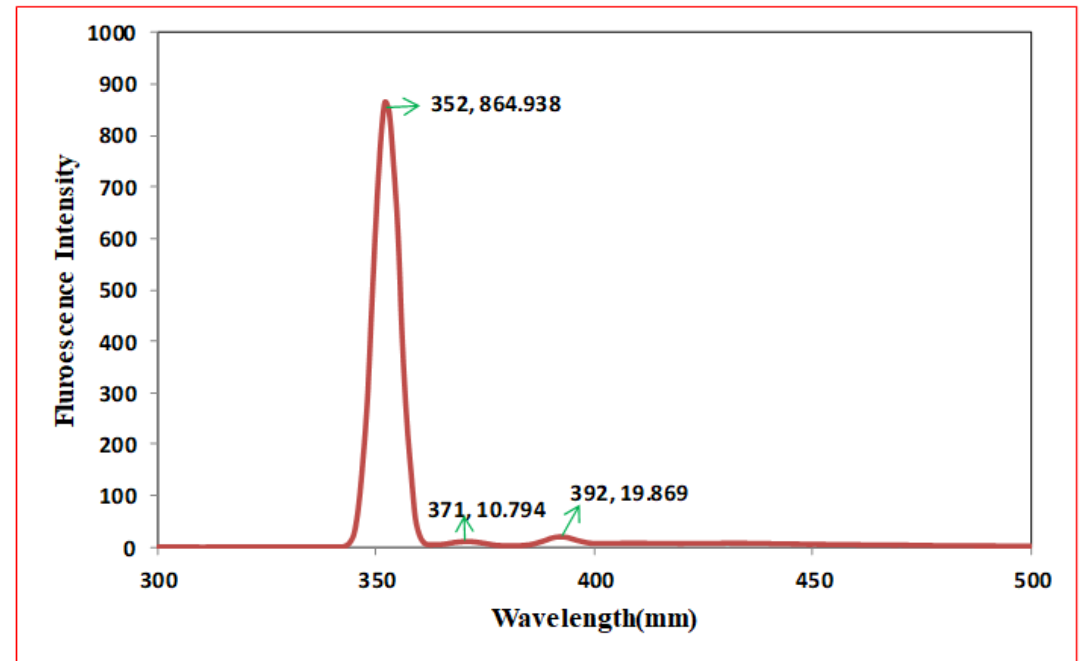

Fig. 6: Fluorescence spectrum of CBZ in DMF 
www.ijpsonline.com

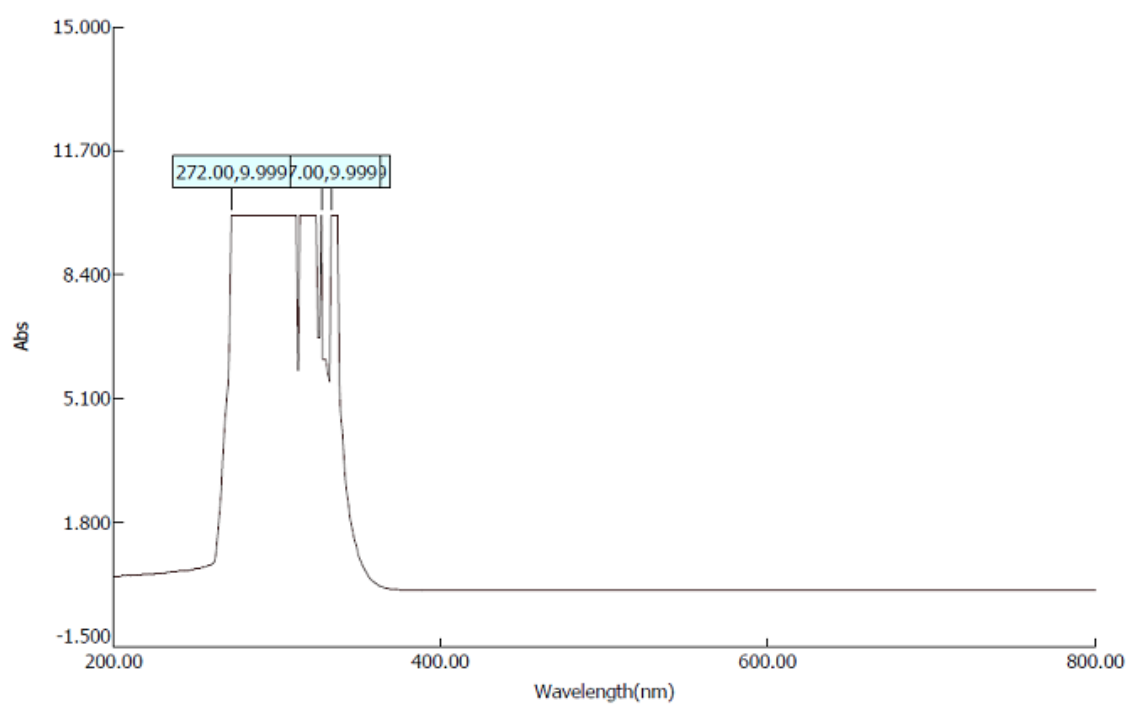

Fig. 7: $U V$ spectrum of $C B Z+C_{10} F_{18}$ emulsion (with sonication)

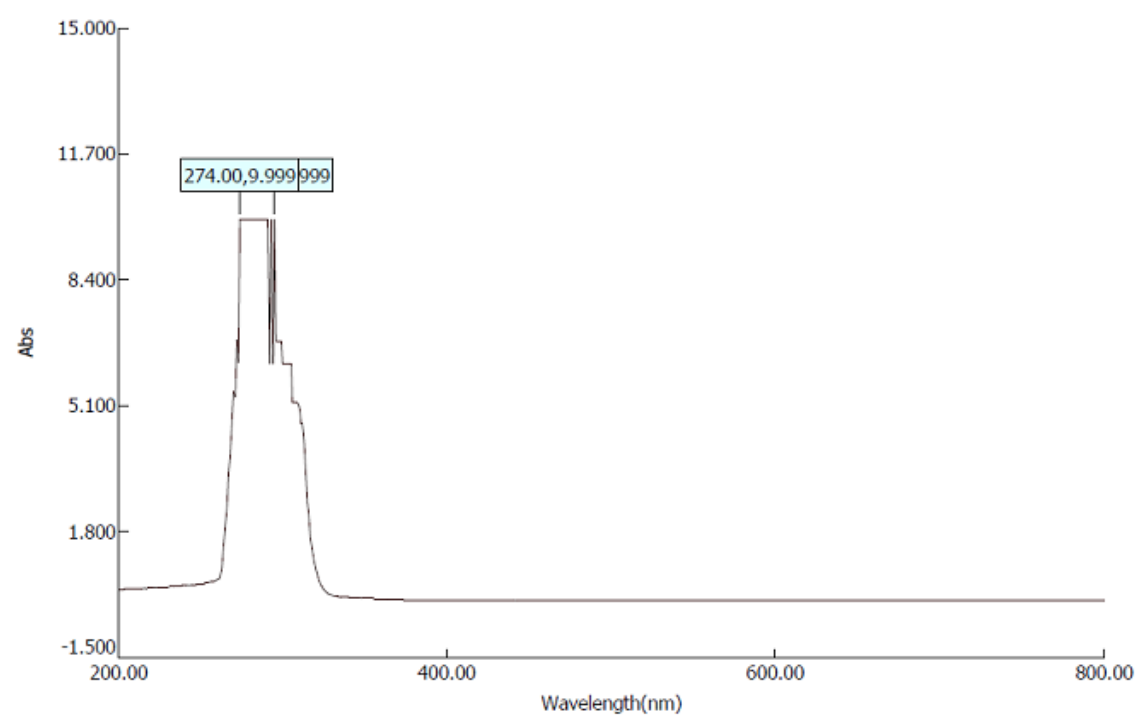

Fig. 8: UV spectrum of $B D Z+C_{10} F_{18}$ emulsion (with sonication)

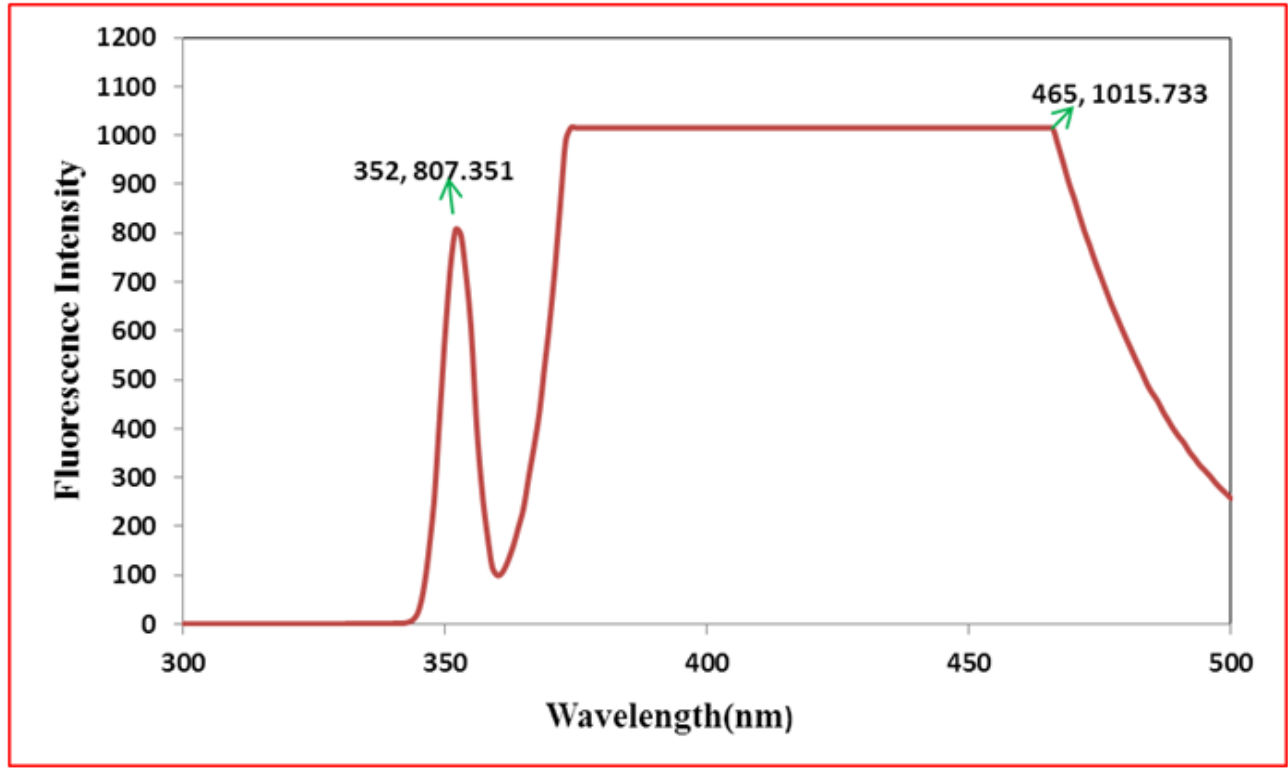

Fig. 9: Fluorescence spectrum of $B D Z+C_{10} F_{18}$ (sonicated emulsion) 


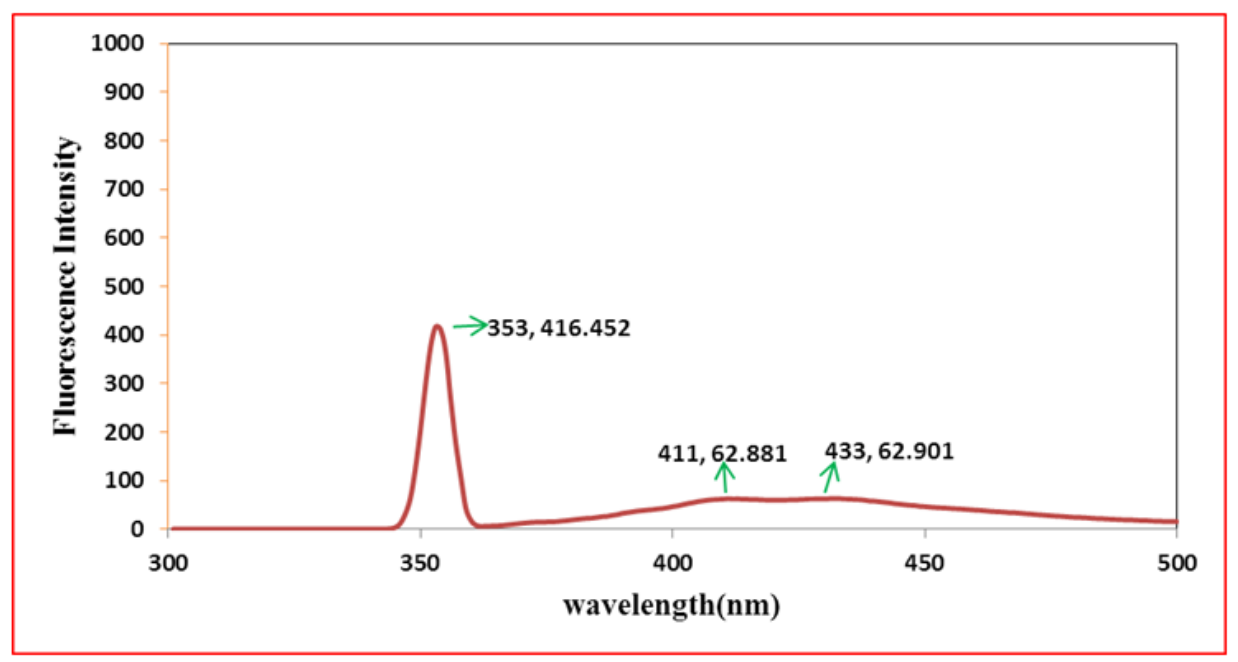

Fig. 10: Fluorescence spectrum of $\mathrm{CBZ}+\mathrm{C}_{10} \mathrm{~F}_{18}$ (sonicated emulsion)
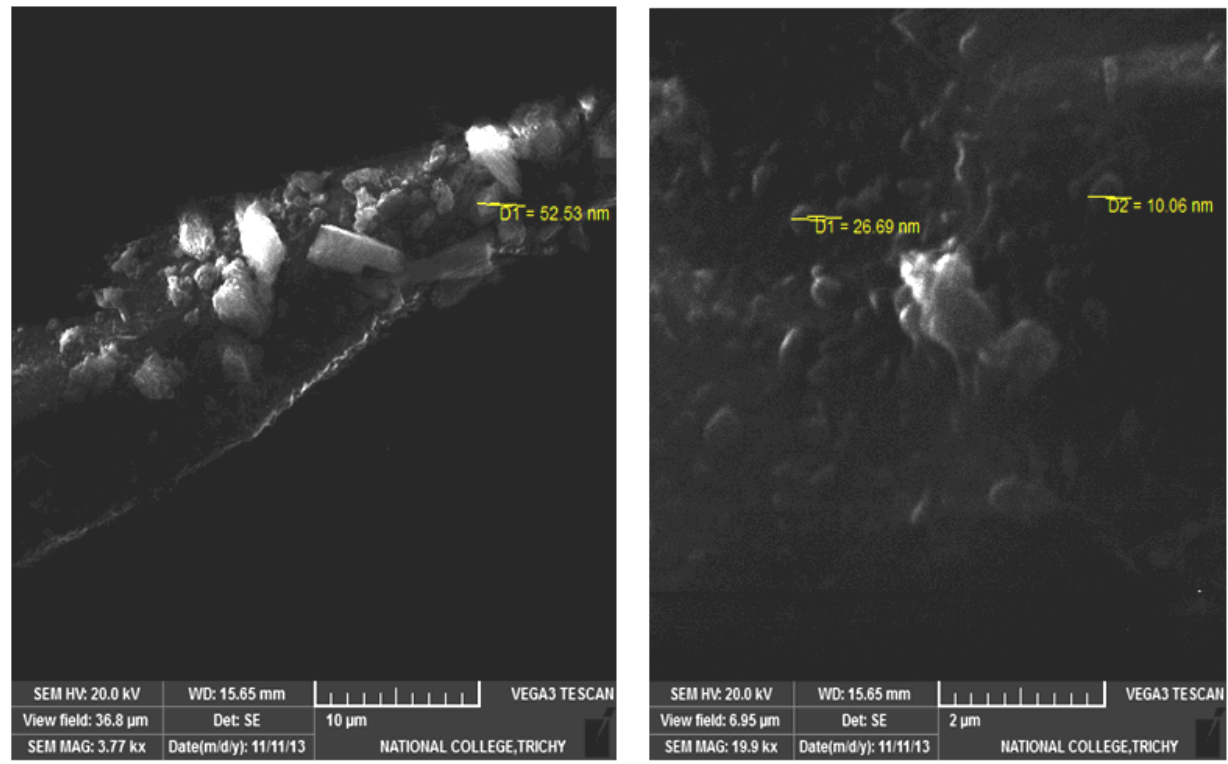

Fig. 11: SEM image of CBZ with PFD $\left(\mathrm{C}_{10} \mathrm{~F}_{18}\right)$ emulsion
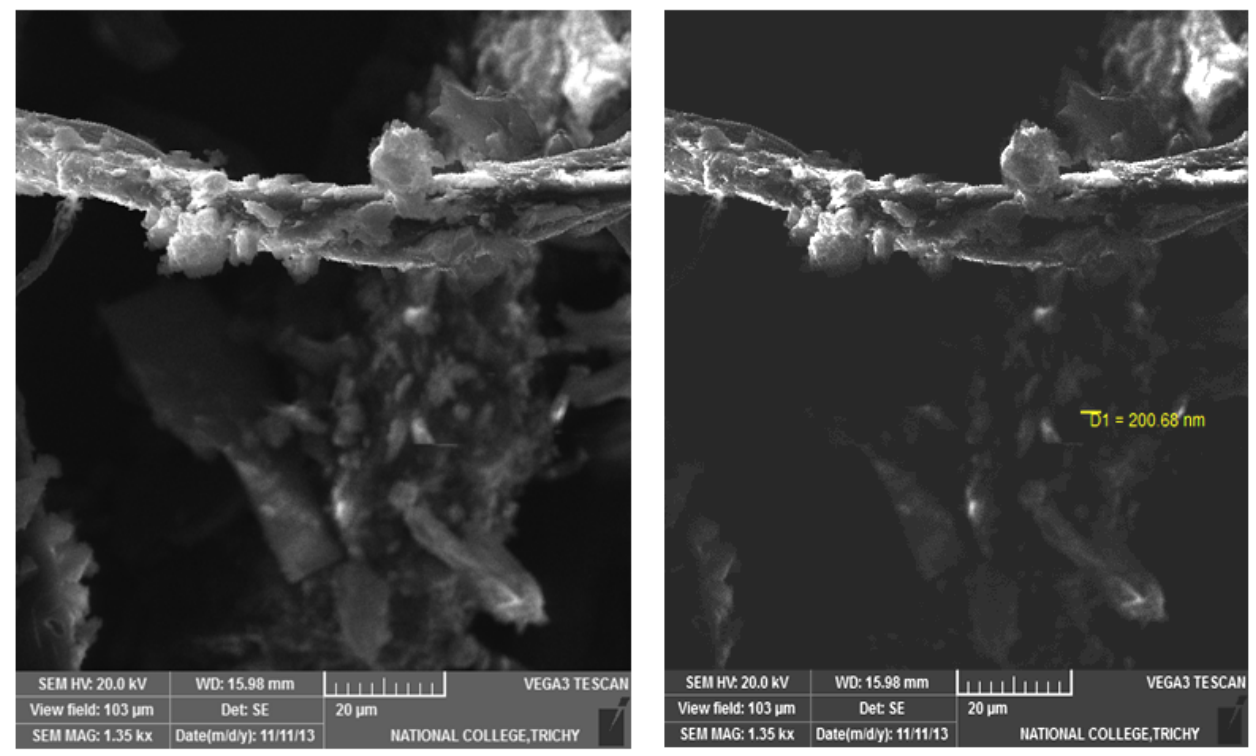

Fig. 12: SEM image of BDZ with PFD $\left(C_{10} F_{18}\right)$ emulsion 
huge difference in the peak height at high concentration as expected ${ }^{[33,34]}$.

Fig. 7-fig. 10 represents the UV-VIS and fluorescence images of diluted emulsion (sonicated). The pronounced increase in the width of the peak indicates the occupancy of the fluorine and carbon. Further there is a steep raise in the peak height indicating the increase in atomic content of both drug and PFD. Both CBZ and BDZ have got a high tendency to accommodate any fluorine compounds for that matter, $\mathrm{C}_{10} \mathrm{~F}_{18}$ in this case. The images of fluorescence also back up these features. The neighbouring peak of the principle maximum is a clear indication.

Due to its structure PFD is insoluble in water and DMF. It has lower diffusion coefficient and higher interfacial tensions ${ }^{[35,36]}$. On the other hand, CBZ and $\mathrm{BDZ}$ too are less soluble in water. But they are highly soluble in DMF. Hence when dissolved in DMF they should possess higher diffusion coefficient and lower interfacial tensions. This is in absolute contrast to PFD. This behaviour favours much for the presence of adequate fluorine and the drug together for longer period of time. The high oxygen dissolving capacity of PFD too is well reflected in the constant value of absorption over a long wavelength. The same is the case in fluorescence intensity images too.

ULD study is carried out here. Table 1 presents the ultrasonic velocity and compressibility of PFD exclusively and for the diluted emulsions of both CBZ+PFD and BDZ+PFD. A drastic increase, almost twice, could be observed in the velocity. Since, the compressibility $\beta=1 / \mathrm{U}^{2} \rho$, the value of $\beta$ has reduced to half, indicating the reduction in molecular interaction energies ${ }^{[37,38]}$. Hence the feasibility of both the drug and PFD existing together in the form of emulsion for a longer period of time is substantiated.

SEM images represent morphology and confirm the shape and size of the particles. Fig. 11 represents the SEM images of CBZ with PFD emulsion and fig. 12 represents the $\mathrm{BDZ}$ with $\mathrm{PFD}$ emulsion. In the case of $\mathrm{CBZ}$, the particle diameter ranging from 10.06 $\mathrm{nm}-52.53 \mathrm{~nm}$ (fig. 11) is an excellent evidence for the hydrogen through fluorine, whereas, BDZ tends to bond with PFD to a greater extent. The diameter of $200.68 \mathrm{~nm}$ (fig. 12), though it is reasonably high, this could be an indication of greater accumulation of fluorine and carbon atoms along with the components of drug. Probably this could be the expected tendency and result. This supports not only smooth transport behaviour but also the excess oxygen uptake by the system/drug throughout the transvascular route. This behaviour of the drug along with PFD supports neurolung protective strategy. This in turn enhances the activity of the AEDs.

All these results presented were to identify the presence of adequate fluorine atoms, carbon content and the components of the drug together in a single emulsion. Studies made seem to support the basic expectation of coexistence of both drug and fluorine atoms together to ensure both the oxygen discharge and the antiepileptic activity.

In conclusion, the expectation of PFD along with any of the AEDs as a single organised crystal with a definite structure is far-fetched. This is because of the basic fact that PFD possess a highly neutral structure. But its high electro negativity helps to co-exist with any chosen antiepileptic drug. The incorporation of one or more fluorine atoms into a compound can have a dramatic effect on its chemical and physical properties and fluorinated molecules are of considerable importance in a wide range of industries including pharmaceuticals, agrichemicals, medical imaging, plastics, polymers and electronics. However the synthesis of these important molecules is fundamentally difficult due to the high reactivity of fluorinating agents. Hence the attempt to come out with a neuro-lung protective strategy, that involves enrichment of both seizures and lungs with oxygen content through the support of PFD (an excellent oxygen carrier) $\mathrm{C}_{10} \mathrm{~F}_{18}$ (PFD) along with an enhancement in the antiepileptic activity should complement the control of prolonged and harmonic vibrations specifically in Lennox-Gastaut type of seizures.

\section{Acknowledgements:}

The authors would like to acknowledge financial assistance from Defence Research \& Development Organization (DRDO), New Delhi, India.

\section{Conflict of interests:}

The authors declared no conflict of interest.

\section{REFERENCES}

1. Aldenkamp AP, Krom MD, Reijs R. Newer antiepileptic drugs and cognitive issues. Epilepsia 2003;44:21-9.

2. Tromp SC, Weber JW, Aldenkamp AP, Arends J, vander Linden I, Diepman L. Relative influence of epileptic seizures and of epilepsy syndrome on cognitive function. J Child Neurol 2003;18(6):407-12.

3. Feely M. Drug treatment of epilepsy. Br Med J 1999;318:1069.

4. Brodie MJ, Dichter MA. Established antiepileptic drugs. 
Seizure 1997;6(3):159-74.

5. Vermeulen J, Aldenkamp AP. Cognitive side-effects of chronic antiepileptic drug treatment: a review of 25 years of research. Epilepsy Res 1995;22(2):65-95.

6. Meador KJ. The conginitive effects of the new AEDs. Neurologist 1998;4:S35-9.

7. Carne RP, O'Brien TJ, Kilpatrick CJ, MacGregor LR, Hicks RJ, Murphy MA, et al. Temporal lobe epilepsy. J Neurosurg 2005;103(4):768-9.

8. Delanty N, French J. Treatment of Lennox-Gastaut Syndrome. CNS Drugs 1998;10(3):181-8.

9. Michoulas A, Farrell K. Medical management of LennoxGastaut syndrome. CNS Drugs 2010;24(5):363-74.

10. Sankar R. GABA A receptor physiology and its relationship to the mechanism of action of the 1,5-benzodiazepine clobazam. CNS Drugs 2012;26(3):229-44.

11. Falip M, Salas-Puig X, Cara C. Causes of CNS inflammation and potential targets for anticonvulsants. CNS Drugs 2013;27(8):611-23.

12. Murphy JV, Patil AA. Stimulation of the nervous system for the management of seizures. CNS Drugs 2003;17(2):101-15.

13. Brunbech L, Sabers A. Effect of antiepileptic drugs on cognitive function in individuals with epilepsy. Drugs 2002;62(4):593604.

14. Coppola G. Treatment of partial seizures in childhood. CNS Drugs 2004;18(3):133-56.

15. Perucca E. The pharmacology of new antiepileptic drugs. CNS Drugs 2011;25(11):909-12.

16. Lenkov DN, Volnova AB, Pope AR, Tsytsarev V. Advantages and limitations of brain imaging methods in the research of absence epilepsy in humans and animal models. J Neurosci Methods 2013;212(2):195-202.

17. Natchimuthu V, Jayalatha KA, Ravi S. Characterizing the molecular interaction of perfluorocarbons with carbamazepine and benzodiazepine using photo-acoustic studies. J Mol Liq 2016;218:120-7.

18. Natchimuthu V, Thomas S, Ramalingam M, Ravi S. Influence of perfluorocarbons on Carbamazepine and Benzodiazepine for a neuro-lung protective strategy. J Clin Neurosci 2017;43:82-8.

19. Viry L, Moulton SE, Romeo T, Suhr C, Mawad D, Cook M, et al. Emulsion-coaxial electrospinning: designing novel architectures for sustained release of highly soluble low molecular weight drugs. J Mater Chem 2012;22(22):11347-53.

20. Lowe KC. Perfluorochemical respiratory gas carriers: benefits to cell culture systems. J Fluor Chem 2002;118(1-2):19-26.

21. Clark LC, Gollan F. Survival of mammals breathing organic liquids equilibrated with oxygen at atmospheric pressure. Science 1966;152(3730):1755-6.

22. Lowe KC. Perfluorinated blood substitutes and artificial oxygen carriers. Blood Rev 1999;13(3):171-84.

23. Riess JG. Fluorocarbon-based oxygen delivery: basic principles and product development. Blood Substit 1998:101-26.
24. Riess JG. Blood substitutes and other potential biomedical applications of fluorinated colloids. J Fluor Chem 2002;114(2):119-26.

25. Freire MG, Dias AM, Coelho MA, Coutinho JA, Marrucho IM. Aging mechanisms of perfluorocarbon emulsions using image analysis. J Colloid Interface Sci 2005;286(1):224-32.

26. Freire MG, Dias AM, Coutinho JA, Coelho MA, Marrucho IM. Enzymatic method for determining oxygen solubility in perfluorocarbon emulsions. Fluid Phase Equilib 2005;231(1):109-13.

27. Dias AM, Pamies JC, Coutinho JA, Marrucho IM, Vega LF. SAFT modeling of the solubility of gases in perfluoroalkanes. J Phys Chem B 2004;108(4):1450-7.

28. Dias AM, Freire M, Coutinho JA, Marrucho IM. Solubility of oxygen in liquid perfluorocarbons. Fluid Phase Equilib 2004;222:325-30.

29. Sjjoblom J. Surfactant Science Series/61. Marcel Dekker: New York; 1996.

30. Dias AM, Caco AI, Coutinho JA, Santos LM, Pineiro MM, Vega LF, et al. Thermodynamic properties of perfluoro-noctane. Fluid Phase Equilib 2004;225:39-47.

31. Dias AM, Bonifacio RP, Marrucho IM, Padua AA, Gomes MC. Solubility of oxygen in n-hexane and in n-perfluorohexane. Experimental determination and prediction by molecular simulation. Phys Chem Chem Phys 2003;5(3):543-9.

32. Newbury DE, Ritchie NW. Performing elemental microanalysis with high accuracy and high precision by scanning electron microscopy/silicon drift detector energy-dispersive X-ray spectrometry (SEM/SDD-EDS). J Mater Sci 2015;50(2):493518.

33. Crison JR, Weiner ND, Amidon GL. Dissolution media for in vitro testing of water-insoluble drugs: Effect of surfactant purity and electrolyte on in vitro dissolution of carbamazepine in aqueous solutions of sodium lauryl sulfate. J Pharm Sci 1997;86(3):384-8.

34. McClean S, O'Kane E, Hillis J, Smyth WF. Determination of 1,4-benzodiazepines and their metabolites by capillary electrophoresis and high-performance liquid chromatography using ultraviolet and electrospray ionisation mass spectrometry. J Chromatogr A 1999;838(1-2):273-91.

35. Sakai T, Kamogawa K, Nishiyama K, Sakai H, Abe $M$. Molecular diffusion of oil/water emulsions in surfactant-free conditions. Langmuir 2002;18(6):1985-90.

36. Weiss J, Herrmann N, McClements DJ. Ostwald ripening of hydrocarbon emulsion droplets in surfactant solutions. Langmuir 1999;15(20):6652-7.

37. Ravi S, Amoros J, Arockia Jayalatha K. Effective method of characterizing specific liquid fluorocarbon interactions using ultrasound. J Phys Chem B 2008;112(20):6420-5.

38. Ravi S, Kalidoss M, Srinivasamoorthy R, Amoros J. A new empirical structure factor for real liquids using internal pressure. Fluid Phase Equilib 2001;178(1-2):33-44. 